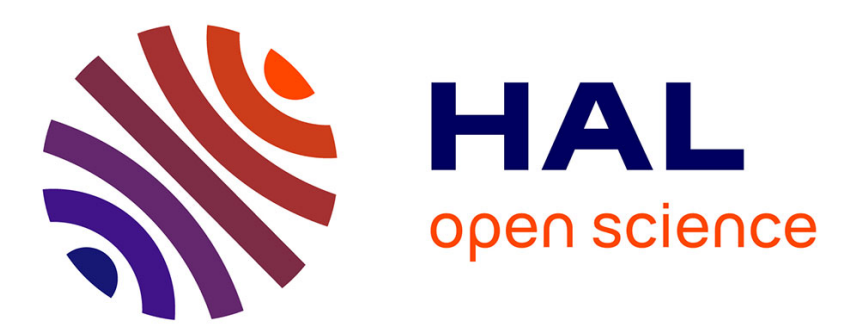

\title{
Language choice adjustments in child production during dyadic and multiparty interactions: A quantitative approach to multilingual interactions
}

\author{
Anna Ghimenton, Jean-Pierre Chevrot, Jacqueline Billiez
}

\section{- To cite this version:}

Anna Ghimenton, Jean-Pierre Chevrot, Jacqueline Billiez. Language choice adjustments in child production during dyadic and multiparty interactions: A quantitative approach to multilingual interactions. Linguistics, 2013, 51 (2), pp.413 - 438. 10.1515/ling-2013-0016 . hal-00718009v3

\section{HAL Id: hal-00718009 \\ https://hal.science/hal-00718009v3}

Submitted on 7 Aug 2013

HAL is a multi-disciplinary open access archive for the deposit and dissemination of scientific research documents, whether they are published or not. The documents may come from teaching and research institutions in France or abroad, or from public or private research centers.
L'archive ouverte pluridisciplinaire HAL, est destinée au dépôt et à la diffusion de documents scientifiques de niveau recherche, publiés ou non, émanant des établissements d'enseignement et de recherche français ou étrangers, des laboratoires publics ou privés. 


\section{LANGUAGE CHOICE ADJUSTMENTS IN CHILD PRODUCTION}

Ghimenton, A., Chevrot, J.-P. \& Billiez, J. (in press). Language choice adjustments in child production during dyadic and multiparty interactions: a quantitative approach to multilingual interactions, Linguistics 51(2).

\section{Language choice adjustments in child production during dyadic and multiparty interactions: a quantitative approach to multilingual interactions}

Anna Ghimenton, Jean-Pierre Chevrot, Jacqueline Billiez

Université Stendhal, Grenoble 3 (France)

Laboratoire LIDILEM

B.P. 25; Grenoble ; Cedex 09

France

Tel.: $0033(0) 476826813$

Email: ghimenton@yahoo.com

\section{Abstract}

This paper aims to document two adjustment types motivating code choices in early production in the multilingual context of Veneto (Italy), where the regional dialects and Italian share the same geolinguistic space. Languages with which a child comes into contact in his/her environment could provide a vantage point for the study of early contextual language adjustments. We compared the early production of a child - Francesco (17-30 months) - with his input, through a quantitative lexical approach to the material. Data were collected in an ecological family setting. Dyadic interactions (15 hours) were taped in Francesco's home and multiparty interactions (20 hours) were recorded in his grandparents' home. In the first setting, statistically-driven acquisition could justify the adjustments in Francesco's production to the language choices in his home environment. In the second setting, where social interaction is different, pragmatically motivated adjustments are more likely to ground Francesco's choices. Results from the analyses suggest that a) child-directed speech promotes steady acquisition of the language which is selected the most frequently in the input and that b) pragmatically explicit interactional contexts could favour the production of lesser used languages. 


\section{LANGUAGE CHOICE ADJUSTMENTS IN CHILD PRODUCTION}

\section{Introduction}

Communicative activity requires the adjustment of linguistic behavior which is appropriate to the interactional setting. In fact, speakers make inferences from the communicative setting in order to make the appropriate language choices, which in their turn may provide modifications to the setting itself (Clark 2009; Gumperz 1977). In the early stages of language development, children have to learn appropriate linguistic behaviors in order to communicate effectively. In multilingual settings, children have the added task to adjust not only their stylistic choices, but also their language choices to the ones of their interlocutors. Our study aims to put forward novel ideas both in the contexts of monolingual and multilingual acquisition, as the language processes in multilingualism could be compared to those involved in monolingual acquisition (Macwhinney 2005).

A growing number of studies show that children as early as two years of age adjust their language choices to the general characteristics of the interaction context, for instance to the parents' preferred language (Fantini 1985; Genesee et al. 1996; Quay 2008). However, the statistical relations between the input and output language patterns have not been described in a multilingual context, as has been done in a monolingual context (see inter alia Behrens 2006; Lieven et al. 2003). This type of study would lead to a better understanding of the reasons underlying the early emergence of language choice adjustments according to the interactional context.

Infants' precocious capacity to extract statistically recurrent patterns in the input is said to be a fundamental element steering language learning (Perruchet \& Pacton 2006). Children use these patterns to unravel the grammatical structure of the language(s) spoken in their environment (Aslin et al. 1998). However, the regularities extracted have to be socially inscribed in order for language construction to be meaningful (Khul 2004; Tomasello 2000). Indeed, the child learns linguistic symbols together with their communicative functions and thus the child grounds the recurrent patterns pragmatically within their social context (Clark 1978; Goldberg 2006; Tomasello 2003a). Hence, speaking is an activity which is intertwined with the social context in which it is performed. It is for this reason that speaking requires the ability to use language appropriately, adjusting it to the context of interaction, which implies the choice of adequate registers and styles (Bell 1984).

As far as acquisition in multilingual contexts is concerned, children's adjustment processes have been explored from various points of view. Lanza (1992) observes that the amount of code-mixing a child produces depends on many factors, including the caregivers' attitudes 


\section{LANGUAGE CHOICE ADJUSTMENTS IN CHILD PRODUCTION}

towards language mixing. Thus, it can be deduced that children are sensitive to production in their language environment and behave accordingly. Nicoladis (1998) corroborates Lanza's observations in her study of a bilingual Portuguese (Brazilian)/English child's production from the ages of $1 ; 0.14$ to $1 ; 6.6$. She observes that, very early in development, the child adjusts her lexical choices to her interlocutor's language. Likewise, Juan-Garau \& PerezVidal (2001) examine the impact of pragmatic factors on the development of a bilingual Catalan/English child, aged $1 ; 3$ to $4 ; 2$. The child increases the production of the minority language, in this case English, when speaking to the father, who provides the child with an exclusively English input produced in pragmatically diverse interactions.

Drawing from the considerations above, we will discuss the possible reasons for a child's precocious language choice adjustments to the multilingual choices made in her environment. More precisely, in this study, we focus on the role and the complementary aspects of two possible sources of motivation for these adjustments. Firstly, adjustments could be the result of statistical learning from the code choices in the input the child's caregivers provide. For instance, the availability of specific lexical items from each language spoken in the child's environment could depend directly on their rate of production in the caregivers' input. In other terms, if the child is exposed to frequently occurring types from one particular language, then s/he will likely memorize and produce more items from this language. Hence, in a multilingual environment the child's caregivers' selection of a specific language may render certain words or chunks more available for child, and eventually favor the acquisition of the languages most frequently used in the input (see Pearson et al. 1997). Dopke (1998) provides evidence for such availability in the input of multilingual children. She shows that bilingual children overgeneralize the syntactic structures of the language they hear the most. Children are thus sensitive to the patterns occurring in the language input. Yet, social factors influence this sensitivity (Kuhl 2004; 2007). Thus frequency effects cannot be dissociated from the social context in which they occur. In other terms, in language acquisition, the child associates language patterns with the social contexts of production. Given the close relationship between frequency and context, it is important to consider the social characteristics of the interactions when dealing with developmental data quantitatively. This leads us to the second source of motivation for the adjustments observed in a multilingual child's production that is pragmatic factors grounding the interactions. In fact, children's language choice adjustments could be guided by the pragmatic intentions speakers convey in the interaction, as it has been shown in studies of multilingual adult interactions (Gumperz 1982; Lüdi \& Py 1986; Mondada 2007; 
Moore 2002; Zentella 1997). Dealing with multilingual data, Genesee, Boivin \& Nicoladis (1996) observed four bilingual French/English two-year-olds. Their aim was to examine how these children used the languages spoken in their environment. The children showed that they were able to judge the language preferences of their interlocutors and to adjust their productions following their judgments. More generally, the child may understand that the use of a specific language is appropriate to the speaker's expectations and thus will associate the use of specific chunks or lexical items of a language with specific communicative intentions, such as complicity with the interlocutor.

This paper aims to describe various adjustment types that affect code choices during interactions between Francesco - aged 17 to 30 months - and his family members. All members come from Veneto, north-eastern Italy. Here, children experience daily exposure to multilingual utterances drawn from the national and regional languages spoken in the social repertoires (Marcato 2002).

Multilingual contexts provide a wealth of linguistic material and are useful for the observation of the nature of adjustments. In such contexts, speakers' lexical choices can be assigned to a specific language category. In this study, we analyze the characteristics of the language choice adjustments. Systematic assignment of each lexical unit was done by placing words in the language categories they belong to.

By using a quantitative approach, we will first investigate the language choices in the child's nuclear family context. The first analysis gives a general picture of the proportions of each language in the child's production and in his home environment. The second analysis will focus more precisely on the proportions of each language within dyadic interactions, between the child and his mother. These data come from a longitudinal corpus (13 months), which allowed us to observe the child's long-term adjustments to the language choices of his mother. The third analysis investigates the child's short-term adjustments (11 days) when interacting with interlocutors with whom he is not in regular contact. Bringing the results of these three analyses together, we will put forwards criteria which may help discern the characteristics of adjustments which are statistically-driven from those that are pragmatically-based.

\section{Sociolinguistic description of Veneto}

Veneto exemplifies Italy's multilingualism by the co-existence of regional dialects - which together form a dialect koinè, based on the features of the most prestigious variety, the variety spoken in Venice (Zamboni 1979) - and Italian. It should be noted that the italoromance 


\section{LANGUAGE CHOICE ADJUSTMENTS IN CHILD PRODUCTION}

dialects are not simplified versions of Italian. They are languages in their own right and each boasts an autonomous historical background (Berruto 2005). In particular, Veneto's dialect has a prestigious historical and political background, which may explain its wide community of practices (Zamboni 1998, 2002) ${ }^{1}$. Thus, Veneto's dialects show resilience to the dominant process of Italianization of the other regional varieties (Coveri et al. 1998). The contact between regional dialects and Italian creates intermediate varieties from lexical, phonological and morphosyntactic points of view. This explains why sociolinguists advocate that it would be more precise to refer Regional Italian, that is to say the regional varieties of standard Italian, rather than Italian tout court (Berruto 1974; Grassi et al. 1997) ${ }^{2}$.

In social interactions speakers can draw from the various linguistic and stylistic repertoires available from both Italian and dialect varieties, creating a continuum of usages between the varieties in contact (Berruto 1993; Cortelazzo 2001; Cortelazzo \& Paccagnella 1997). Sociolinguistic studies conducted in this area show that the dialect varieties are a communicational asset and constitute an important element of the linguistic resources available to speakers for daily usage (Alfonzetti 1992; Berruto 2005; Gamberini 1999; Giacalone-Ramat 1995). Despite the richness of the language resources in the italoromance repertoires, multilingualism has seldom been the key of investigation in acquisition studies conducted in Italy. Sociolinguistic studies have focused primarily on the contact phenomena in the romance speech communities, while psycholinguistic studies have given preference to Italian language acquisition. The separate focus of these two disciplines has undoubtedly precluded attempts at cross-fertilization of psycholinguistic and sociolinguistic approaches in the italoromance situation.

The decision to analyze the child's language environment in its entirety, that is, by including the dialect varieties, Italian and the variation resulting from their contact, was motivated by the theoretical framework chosen for the present study: the usage-based account to language acquisition (Bybee 2008; Bybee \& Hopper 2001; Tomasello 2003a). According to this account, language exposure and usage constitute two major pillars which support language construction. Hence, failure to consider the multilingualism to which children growing up in

\footnotetext{
${ }^{1}$ A According to the UNESCO's Red Book of Endangered languages, the Veneto dialect is not considered to be a threatened language minority, unlike other italoromance varieties, such as Sardinian or Piedmontese for example, which are considered to be endangered languages.

(http://www.helsinki.fi/ tasalmin/europe_index.html).

${ }^{2}$ For sake of simplicity, we will use the term Italian when referring to the regional realisation of Standard Italian (i.e. regional Italian).
} 


\section{LANGUAGE CHOICE ADJUSTMENTS IN CHILD PRODUCTION}

Veneto are exposed would indeed ignore important information about the pathways involved in the construction of the languages used in their community.

\section{Methodology}

The two main aims of the study motivate its design. Firstly, we wanted to investigate statistical and pragmatically driven adjustments to the interaction context without introducing an experimental protocol. Secondly, we focused our investigation on the language choices in the input and in the output. Hence, the study was undertaken in an ecological setting where Francesco was observed in two contrasting family contexts. In these two settings, Francesco's language choices, as well as those of his interlocutors, are examined. The results presented in the paper are derived from an in-depth analysis of the input-output patterns of speakers' code choices and of the variability of these patterns depending on the interaction setting.

\subsection{Description of the two interactional settings}

In the first setting, Francesco took part in a 15-hour longitudinal study where he was recorded roughly on a monthly basis between the ages of 17 to 30 months. The length of the monthly recordings varies, ranging from one to two hour long sessions. The taping sessions in this type of data collection took place in the child's home. At the time of the study, Francesco was an only child and did not attend nursery school. Hence, in the interactions recorded, his family nucleus language environment consisted of adult interlocutors. In this corpus, focus is placed mainly on the dyadic exchanges between Francesco and his mother, as she was the child's principal caregiver during the recording period. Mother-child interactions were thus considered to be sufficiently representative of the child's daily language exposure and production setting at the time of the recordings. Other speakers' production was taken into consideration, but did not feature in more detailed analyses.

The data from the second corpus were collected in a very different and relatively unfamiliar interactional setting. The child was recorded in multiparty interactions during family mealtimes. A total of 16 hours were taped. These recordings were made in the child's grandparents' home. At the time of the recordings the child was aged 25 months. $\mathrm{He}$ interacted with five different interlocutors: two of them (his parents) were familiar to him, while the other three (his maternal grandparents and an aunt) were relatively unfamiliar ${ }^{3}$. The familiarity of the speakers depended on the frequency with which the speakers were in contact

\footnotetext{
${ }^{3}$ The aunt is the first author of this paper. She lives in France and visits the child's family five times yearly.
} 


\section{LANGUAGE CHOICE ADJUSTMENTS IN CHILD PRODUCTION}

with the child. Francesco's grandparents and aunt moved from Veneto to South Africa in the early nineties. Similarly to other immigrant communities from Veneto, the grandparents have maintained bilingual dialect/Italian family usage ${ }^{4}$. Presently, the grandparents reside in South Africa and the aunt lives in France. Despite the geographical distance between the members of the extended family from the mother's side, they gather together in the grandparents' home once yearly during the Christmas vacation.

\subsection{Word assignment}

The interactions recorded were transcribed orthographically. In order to analyze the language choices in the input and the output, we performed a word-level coding of the utterances: each word token was placed in a language category. Although a word-level coding is not common, we thought it was a useful way of measuring with precision the extent to which each language was represented in each utterance. In this way, an utterance containing for example two Italian words and one dialect word was analyzed differently to another utterance containing two dialect words and one Italian word. Even though these are two mixed utterances, the languages involved in the mixing are not represented in equal proportions. Hence, utterances were analyzed in terms of the proportions in which the various languages are represented in each speaker's discourse.

As previously mentioned, the linguistic continuum created by the languages in contact means that on lexical, phonological and morphosyntactic levels there are numerous areas of overlap. In fact, the joint usage of dialect and Italian in the same geolinguistic space seems to blur the language borders that distinguish each language from the others. These areas of overlap had to be dealt with accordingly, particularly in the word assignment task we had set out for the quantitative analyses.

We addressed the issue by establishing three functional categories. Lexical items that belonged unequivocally to Italian or dialect lexicon were placed respectively in the Italian and dialect categories. Reference books on both Italian and dialect grammars and vocabulary were used in order to further justify the word assignment we performed as native speakers of both Italian and dialect (Dardano 1994, 2005; Marcato \& Ursini 1998).

\footnotetext{
${ }^{4}$ Numerous studies have been conducted in these communities. For instance, Corrà (2001) and Marchiaro (2001) have investigated the dialect preservation of the Veneto immigrant community in Brazil whereas Frosì (2001) focused her study on the Veneto community settled in Argentina.
} 


\section{LANGUAGE CHOICE ADJUSTMENTS IN CHILD PRODUCTION}

The third category was labelled continuum. This contained items that could figure in both Italian and dialect lexicon. The elaboration of these three categories prevented the overestimation of one language above the other. Two linguists working in the Italo-Romance field reviewed the transcription ${ }^{5}$. The word assignment task we performed was assessed by a dialectologist, specialized in Italo-Romance linguistics. Based on 170 utterances (845 words), the rate of agreement with the initial transcriber is good (Cohen's kappa $=0.8$ ). Below, we have provided a linguistic example of the way in which the data have been coded.

(1) Varda varda come che el tira su a frégoea.
Look look how that he picks up the breadcrumb

'Look at how he picks up the breadcrumb'.

In (1), all the words contained in this utterance Francesco's grandmother produced were placed in the dialect category, with the exception of come che and tira su which were placed in the continuum category, as both can be used in either an Italian or dialect speaking context. In fact, should utterance (1) be produced in Italian, it would be as follows:

Dial.: Varda varda come che el tira su a frégoea.

Ital.: Guarda guarda come che $Q$ tira su la bricciola.

As it can be noticed, dialect, unlike Italian, is not a pro-drop language. Hence, in this context, the presence of the subject pronoun is compulsory in dialect but not in Italian (see Poletto 2000, for more detail on this topic). Moreover, comparing the dialect utterance with the Italian one, the only lexical items which remain the same are come che and tira su. Both items are attested in the northern regional Italians as well as in the regional dialects. In general, each item that was placed in either Italian or dialect categories had a corresponding item in either language. In the quantitative analyses, lexical items in utterances like (1) were counted as follows: five dialect elements (varda, varda, el, a, frégoea); two continuum items (come che; tira su). As it can be seen, items like come che and tira su, were counted as single occurrences. In the former, come che is a usual conjunction occurring in the regional varieties of Italian spoken in northern Italy. As for tira su, the verb tirar (dial.) / tirare (Ita.) means 'pick up' only if it is followed by the particle $s u$, or else it means 'pull'. In the analyses that follow, quantitative measures of the distribution of the code choices were analyzed by means of these three categories.

\footnotetext{
${ }^{5}$ Two dialectologists were involved in this part of the research: Giovanni Depau and Maria Teresa Vigolo. We express our gratitude for their help and numerous suggestions.
} 


\section{Analysis of the language choices in the child's input and output in his home environment (longitudinal study)}

The first part of the analyses (see Sections 4.1 and 4.2) is drawn from the first interactional setting. The child was taped during his daily activities (mainly play and mealtimes). His main interlocutors were his parents, in particular his mother. His paternal grandparents and maternal grandmother visited occasionally. We first looked at language production in interactions between Francesco and his two parents as well as his parents' productions when they talk to one another. However, special focus has been placed on the mother-and-child dyadic interactions, given that at this stage she was the child's main caregiver.

\subsection{General production in the child's input and output during interactions in his home environment}

As a first approach to the longitudinal data, we wanted to obtain a general imprint of the child's language choices as well as those to which he is exposed in his home environment. The results that follow were analyzed in the average percentage of words in each category (dialect, continuum, Italian) per utterance. We analyzed the production in six different dyads (see column "Dyads"): two involved inter-adult production and four involved production between one parent and the child. Under each dyad, we have placed the number of utterances produced in the dyad. For example, when the child's mother addresses the father (see line "Mother to father"), the 124 utterances she produces contain, on average, 53\% of dialect words, $36.7 \%$ of continuum words and $10.3 \%$ of Italian words.

Table 1. Average percentages of dialect, continuum and Italian words per utterance produced in inter-adult dyads and adult-child dyads

\begin{tabular}{|l|c|c|c|}
\hline $\begin{array}{l}\text { Dyads } \\
\text { (Total occurrences) }\end{array}$ & Dialect & Continuum & Italian \\
\hline $\begin{array}{l}\text { Mother to father } \\
\text { (N=124) }\end{array}$ & $53 \%$ & $36.7 \%$ & $10.3 \%$ \\
\hline $\begin{array}{l}\text { Father to mother } \\
\text { (N=93) }\end{array}$ & $50.8 \%$ & $40.7 \%$ & $8.5 \%$ \\
\hline $\begin{array}{l}\text { Mother to child } \\
\text { (N=2016) }\end{array}$ & $1.1 \%$ & $35.3 \%$ & $63.6 \%$ \\
\hline $\begin{array}{l}\text { Father to child } \\
\text { (N=291) }\end{array}$ & $2.5 \%$ & $50.1 \%$ & $47.4 \%$ \\
\hline $\begin{array}{l}\text { Child to mother } \\
\text { N=1872) }\end{array}$ & $2.9 \%$ & $45.3 \%$ & $51.8 \%$ \\
\hline $\begin{array}{l}\text { Child to father } \\
\text { (N=160) }\end{array}$ & $4.4 \%$ & $71.1 \%$ & $24.5 \%$ \\
\hline
\end{tabular}

When speaking to the child's father, the mother's production of Italian, continuum and dialect words is significantly different (Friedman's test: chi2 $=1828.7, \mathrm{p}<0.0001$ ). She uses mostly 


\section{LANGUAGE CHOICE ADJUSTMENTS IN CHILD PRODUCTION}

dialect and her dialect production is significantly greater than her Italian one (Wilcoxon test: $\mathrm{z}$ $=-7.1, \mathrm{p}<0.0001)$. When the father engages in conversation with the mother, the amount of dialect, continuum and Italian words per utterance is significantly different (Friedman's test: chi2 $=113.9, \mathrm{p}<0.0001)$. Similarly to the mother, the father uses more dialect than Italian (Wilcoxon test: $\mathrm{z}=-6.3, \mathrm{p}<0.0001$ ) when he speaks to the child's mother.

Both parents' language choice distribution changes when they speak to the child. In the mother's child addressed speech, the production of dialect, continuum and Italian words per utterance is significantly different (Friedman's test: chi2 $=2648.5, \mathrm{p}<0.0001$ ) and Italian is the language she uses the most and is significantly greater than her dialect production (Wilcoxon test: $\mathrm{z}=-36.3, \mathrm{p}<0.0001$ ). As for the child's father, when he speaks to Francesco the language distribution in his utterances is significantly different (Friedman's test: chi2 $=316.3, \mathrm{p}<0.0001)$. His continuum and Italian productions do not differ significantly (Wilcoxon test: $\mathrm{z}=-0.7, \mathrm{p}<0.5$ ). However, dialect remains the language less frequently selected by the father when speaking to his son and is significantly less than continuum (Wilcoxon test: $\mathrm{z}=-12.9, \mathrm{p}<0.0001$ ) and Italian (Wilcoxon test: $\mathrm{z}=-12.3, \mathrm{p}<0.0001$ ).

Concerning the child's production, the proportions of Italian, continuum and dialect words are significantly different when he engages in conversations with his mother (Friedman's test: chi2 $=1263.9, \mathrm{p}<0.0001$ ) as well as with his father (Friedman's test: chi2 $=111.6, \mathrm{p}<$ 0.0001). When speaking to his mother, Francesco's utterances contain mainly Italian words and very little dialect words. His Italian production is significantly greater than his dialect one (Wilcoxon test: $\mathrm{z}=-28.9, \mathrm{p}<0.0001$ ). Concerning Francesco's production of continuum words towards his mother, it is significantly greater than his dialect production (Wilcoxon test: $\mathrm{z}=-27.9, \mathrm{p}<0.0001$ ) and significantly lower than his Italian production (Wilcoxon test: $\mathrm{z}=-2.6, \mathrm{p}<0.0001)$.

When speaking to his father, Francesco's production reveals a slightly different pattern. His utterances are composed mainly of continuum words. The proportions of continuum words are significantly greater than the proportions of Italian words (Wilcoxon test: $\mathrm{z}=-6.3$, $\mathrm{p}<0.0001$ ) and the proportions of dialect words (Wilcoxon test: $\mathrm{z}=-10, \mathrm{p}<0.0001$ ). Dialect is used the least. The proportions of dialect words per utterance are significantly lower than the proportions of Italian words (Wilcoxon test: $\mathrm{z}=-5.1, \mathrm{p}<0.0001$ ).

This analysis gives a glimpse of the general language choices to which the child is exposed within the family circle. One main result emerges. Inter-adult utterances produced in the child's presence contain mainly dialect words whereas the utterances the child produces and 


\section{LANGUAGE CHOICE ADJUSTMENTS IN CHILD PRODUCTION}

receives contain mainly Italian words. Hence, what appears from the analysis is that Francesco's language choices are similar to those attested in the child-addressed speech.

\subsection{Production in mother and child dyad}

We now focus on a closer analysis of the relationship between the child's language development and the mother's child-directed speech. Data gathered in each month of the tapings were reorganized into five main age periods. Age periods were constructed according to the number of utterances produced (see Table 2, second column), our aim being for each age period to contain a balanced number of utterances, to make it representative of both the child's and the mother's productions. As the previous analysis, the results were analyzed in the average percentage of each category (dialect, continuum, Italian) per utterance. Below the average percentages are the differences between the child's and mother's word production per category expressed in absolute values. For example, in Age period 1, the difference between the child's average dialect production per utterance $(2.9 \%)$ and the mother's one $(1.2 \%)$ is $1.7 \%$.

In the bottom line of Table 2, we reported the minimum and maximum percentages produced for each speaker within each language category across the five age periods. For example, the child's dialect production ranges between $0.4 \%$ (age-period 5) and 8.7\% (age-period 2). Figuring below this production bracket are the absolute values of the differences between the minimum and the maximum percentages. These values provide information on the variation within the speakers' productions across the five age periods. 


\section{LANGUAGE CHOICE ADJUSTMENTS IN CHILD PRODUCTION}

Table 2. Average percentages of dialect, continuum and Italian words per utterance produced in a mother and child dyad within 5 age-groups

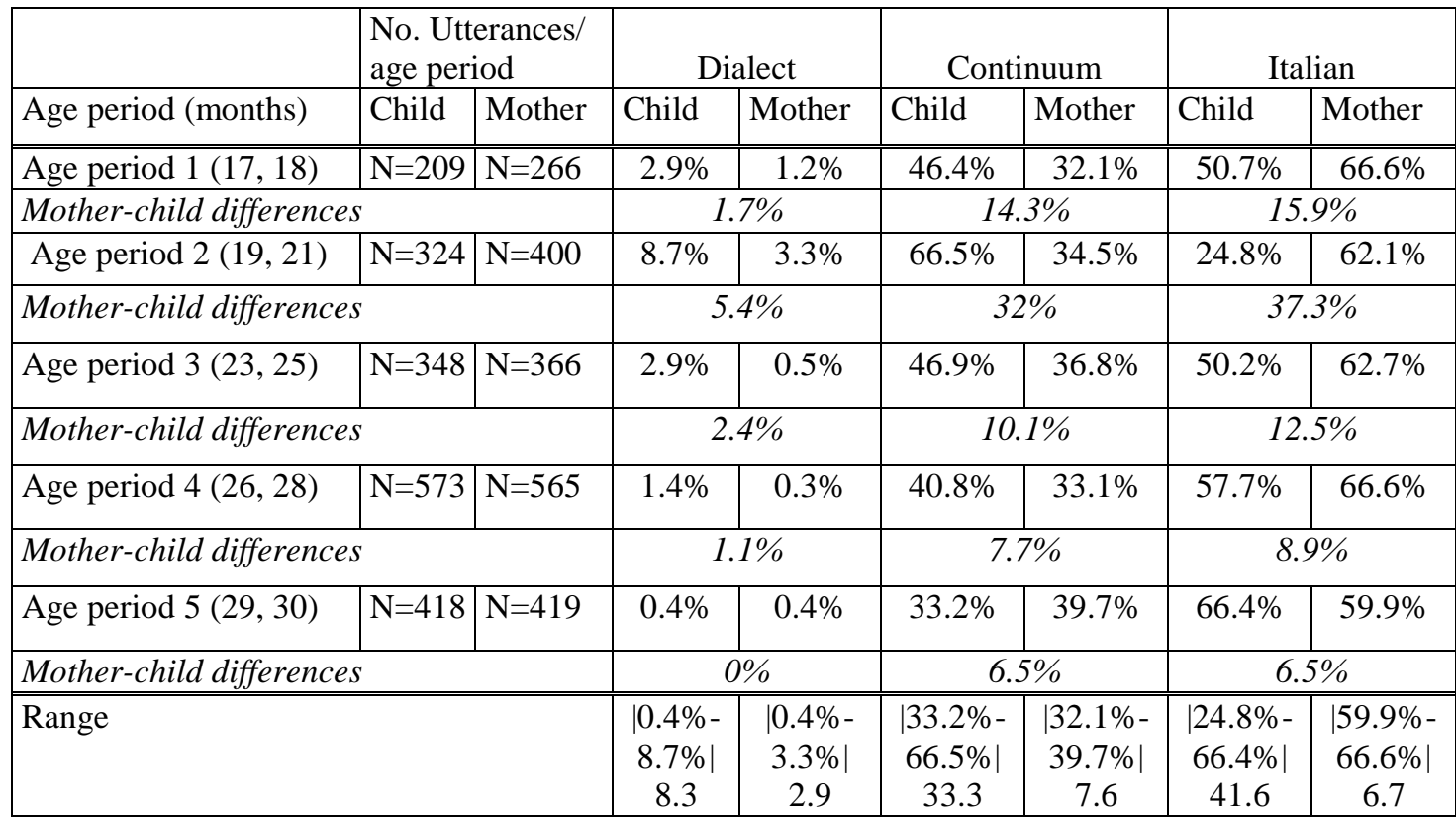

Francesco and his mother produce changing amounts of Italian, continuum and dialect words throughout the age periods (Friedman's test for Francesco: $70.6<\operatorname{chi} 2<405.2, \mathrm{p}=0.0001$; Friedman's test for mother: $307.9<\operatorname{chi} 2<705.2, \mathrm{p}=0.0001)$. Considering this fact, a number of observations may be made. Firstly, in a dyadic interaction between Francesco and his mother, dialect is used seldom and does not surpass $10 \%$. Towards the end of the taping sessions, dialect usage is near to null ( $0.4 \%$ for both speakers). Secondly, the two speakers have a preference for the usage of lexicon belonging to the continuum and Italian categories. Francesco has a continuum usage peak in the second age-period, reaching $66.5 \%$. It then progressively reaches the mother's percentage of usage in the last two age-periods, and remains below 40\%. With the exception of Francesco's production in age-period 2, their Italian production is never below 50\%. It is consolidated in periods 4 ( 26 to 28 months) and 5 (29 to 30 months) and is above 55\%. Vocabulary in the Italian and continuum categories seems to stabilize in the last two age-periods: Italian becomes the predominant language used and vocabulary in the continuum category is in second place. Generally, in mother-and-child dyadic interaction, there is a clear preference for Italian and an avoidance of dialect.

More importantly, for dialect, continuum and Italian, the differences found between the mother and child's productions decrease as Francesco progresses in his language development. The differences tend to decrease in each category as the child grows: from $1.7 \%$ to $0 \%$ for dialect, from $14.3 \%$ to $6.5 \%$ for continuum and $15.9 \%$ to 6.5 for Italian. The question is to know whether it is the child who adjusts to the mother's production or whether 


\section{LANGUAGE CHOICE ADJUSTMENTS IN CHILD PRODUCTION}

it is the mother who accommodates to her child's language choices. To provide an answer to this question, we examined the scores' ranges across the five age periods per language category for both speakers (see last line of Table 2). In each category, the mother's ranges are smaller than those observed in the child's production: 2.9 versus 8.3 for dialect; 7.6 versus 33.3 for continuum; 6.7 versus 41.6 for Italian. This result suggests that it is more likely that the child adjusts to the mother's stable language choices and not vice versa.

The longitudinal study undertaken during a period in Francesco's language development (between ages 17 and 30 months) seems to show two divergent types of production present in Francesco's home environment. Firstly, in child-addressed speech, Italian is the language most frequently used. Secondly, in inter-adult speech, dialect usage is predominant. Despite exposure to inter-adult discourse, Francesco's language choices are more oriented towards those of his mother and, more generally, to those present in the child-directed speech.

In the analysis of production in mother-and-child dyadic interactions, we observed that the child's language choices gradually tend towards his mother's. These results suggest that the adjustments observed in the child's production could be statistically driven. Three dominant characteristics of these adjustments justify the argument in favor of statistical learning. Firstly, these adjustments take place over the long-term: the time of exposure favors the acquisition and production of recurrent language patterns in the environment (in Francesco's case, in the child-addressed speech). Secondly, considering the scores' ranges across the five age periods, the mother manifests the least amount of variation, which suggests that the child adjusts his language choices to those of his mother, and not the contrary. As Francesco's main caregiver, the mother provides him with a reliable source of input and Francesco is more likely to align his language choices with hers. Thirdly, the adjustments were observed in the child's home environment, and thus the one he is most familiar with on a daily basis. The statistical properties of production in his home environment and in particular in the childaddressed speech could have had a strong influence in shaping Francesco's repertoire.

However, statistically-driven learning may not necessarily be the only learning process involved at this stage of development. For example, during interactions with multilingual interlocutors, the child may be sensitive to the particular use of a code in order to communicate specific communicative intentions more efficiently (Genesee et al. 1996). In order to test the child's ability to adjust to the interaction settings, we decided to change the taping setting and observe Francesco in a different environment. Given the young age, we did not choose an environment that was too unfamiliar. Our investigation continued in the child's 


\section{LANGUAGE CHOICE ADJUSTMENTS IN CHILD PRODUCTION}

maternal grandparents' home in South Africa. The child's parents do not have a social circle in South Africa. Therefore when they visit, they mainly remain in a close-knit family interaction context. Within the latter, the child is exposed to extensive multiparty interactions with unfamiliar speakers during a short length of time (11 days). Thus, by changing the interaction setting, long-term adjustments are unlikely to be the grounding factors for the child's possible adjustments to the language choices in the surrounding production. As a result, these interactions could highlight Francesco's ability to capture the pragmatic features (see (2) in discussion for an example of such feature). These features may be associated to the different language choices locally available in the interactions.

\section{Analyses of the language choices in the child's input and output in an unfamiliar environment}

The second part of the analyses studies the language choices in the multiparty interactions in which the child participated during the annual stay at the maternal grandparents' home. There were six main interlocutors: the child, his parents, his maternal grandparents and one aunt. We focused on the language choices in the child's input and output during multiparty interactions.

\subsection{Adults' language choices in child-addressed speech during multiparty interactions}

Tapings were done on five days of the eleven day stay (Days $1 ; 5 ; 6 ; 10 ; 11$ ). The adults' productions were divided in two sub-groups, depending on the frequency of contact the speakers have with the child. The parents constituted the first group, as they have daily contact with the child, whereas his maternal grandparents and the aunt were placed in the second group as they do not have daily contact with the child. 
Table 3. Average percentages of dialect, continuum and Italian words per child-addressed utterance produced within two adult groups; number of utterances appear below average percentage rates

\begin{tabular}{|c|c|c|c|c|c|c|}
\hline Language & Groups of Speakers & Day 1 & Day 5 & Day 6 & Day 10 & Day 11 \\
\hline \multirow[t]{2}{*}{ Dialect } & Parents & $\begin{array}{l}0.6 \% \\
N=277\end{array}$ & $\begin{array}{l}2.1 \% \\
\mathrm{~N}=275\end{array}$ & $\begin{array}{l}3.5 \% \\
\mathrm{~N}=329\end{array}$ & $\begin{array}{l}1.4 \% \\
\mathrm{~N}=307\end{array}$ & $\begin{array}{l}2.7 \% \\
N=277\end{array}$ \\
\hline & Grandparents and aunt & $\begin{array}{l}2.8 \% \\
\mathrm{~N}=268 \\
\end{array}$ & $\begin{array}{l}5.8 \% \\
\mathrm{~N}=228 \\
\end{array}$ & $\begin{array}{l}6.5 \% \\
\mathrm{~N}=144\end{array}$ & $\begin{array}{l}9.1 \% \\
\mathrm{~N}=199 \\
\end{array}$ & $\begin{array}{l}10 \% \\
\mathrm{~N}=228\end{array}$ \\
\hline \multirow[t]{2}{*}{ Continuum } & Parents & $\begin{array}{l}34.2 \% \\
N=277\end{array}$ & $\begin{array}{l}34.7 \% \\
\mathrm{~N}=275\end{array}$ & $\begin{array}{l}35.8 \% \\
\mathrm{~N}=329\end{array}$ & $\begin{array}{l}38.4 \% \\
\mathrm{~N}=307\end{array}$ & $\begin{array}{l}35.8 \% \\
\mathrm{~N}=277\end{array}$ \\
\hline & Grandparents and aunt & $\begin{array}{l}34.3 \% \\
N=268\end{array}$ & $\begin{array}{l}30 \% \\
\mathrm{~N}=228\end{array}$ & $\begin{array}{l}33.2 \% \\
\mathrm{~N}=144\end{array}$ & $\begin{array}{l}33.3 \% \\
\mathrm{~N}=199\end{array}$ & $\begin{array}{l}36.6 \% \\
N=228\end{array}$ \\
\hline \multirow[t]{2}{*}{ Italian } & Parents & $\begin{array}{l}65.3 \% \\
N=277\end{array}$ & $\begin{array}{l}63.2 \% \\
N=275\end{array}$ & $\begin{array}{l}60.6 \% \\
N=329\end{array}$ & $\begin{array}{l}60.2 \% \\
N=307\end{array}$ & $\begin{array}{l}61.3 \% \\
N=277\end{array}$ \\
\hline & Grandparents and aunt & $\begin{array}{l}62.9 \% \\
N=268\end{array}$ & $\begin{array}{l}64.2 \% \\
N=228\end{array}$ & $\begin{array}{l}60.2 \% \\
N=144\end{array}$ & $\begin{array}{l}57.5 \% \\
N=199\end{array}$ & $\begin{array}{l}53.3 \% \\
N=228\end{array}$ \\
\hline
\end{tabular}

Table 3 shows the productions in the two groups' child-addressed speech. Mann-Whitney tests were performed to compare the two groups' productions during six days of the stay for each category. From the tests, the two groups show a divergent dialect usage (for each of the five days, $\mathrm{p} \leq 0.05$ ). The group of "unfamiliar" speakers (the grandparents and the aunt) produces utterances which contain systematically more dialect words than those produced by the child's parents. As for the comparison between the two groups' production in the continuum and Italian categories, except for the continuum productions on day 5 where the difference is significant $(\mathrm{p}=0.02$ ), the tests do not reveal other significant differences (Italian: $0.2 \leq \mathrm{p} \leq 0.8$; continuum: $0.2 \leq \mathrm{p} \leq 1$ ). Hence, the grandparents' and the aunt use more dialect than the parents but the two groups show similar language choices as per the Italian and continuum categories.

Refining our investigation, we tested whether the two groups' productions fluctuate significantly during the stay at the grandparents' home. The non-parametric Kruskal-Wallis tests show that the two groups' dialect productions change significantly $(\mathrm{p} \leq 0.02)$. Yet, it should be noted that the parents' dialect production oscillates between $0.6 \%$ and $3.5 \%$ without a significant directional trend, unlike that observed in the other group's production. In fact, the dialect produced by the grandparents and aunt towards the child increases steadily through the taping period, from $2.8 \%$ and $10 \%$. Italian production shows a different pattern from the dialect one. Francesco's parents do not significantly alter their Italian production in the childaddressed production $(\mathrm{p}=0.4)$. Their production is always above $60 \%$. However, the childaddressed Italian production of the grandparents and the aunt decreases significantly through 
the vacation period $(\mathrm{p}=0.003)$. As for the continuum production observed in the two groups, there are no significant changes $(0.2 \leq \mathrm{p} \leq 0.8)$.

Despite the similar trends found in Francesco's language home environment (predominant Italian and rare dialect usage in child-addressed speech), the two groups of adults use Italian and dialect differently and their production changes during the stay. The next step is to observe the child's adjustments to the two groups' different language usages, within the eleven day stay.

\subsection{Francesco's production in the multiparty interactions}

The adults' child-addressed speech will be presented together with Francesco's production in order to examine the child's ability to adjust his language choices to those of his interlocutors. We kept the same groupings of the child's interlocutors as in Analysis 5.1 (see Table 3). As production in the continuum category does not fluctuate significantly during the recording period, we focused on the Italian and dialect productions only.

The next two tables present the dialect productions in interactions involving the child and his parents (Table 4) and the child and his grandparents and aunt (Table 5). We focus first on the dialect produced in interactions involving Francesco and his parents during the six day tapings.

Table 4.Average percentages of dialect words in Francesco and his parents' production when they participate in the same interaction; number of utterances produced per day figure below percentages

\begin{tabular}{|l|l|l|l|l|l|}
\hline Pairs of interlocutors & Day 1 & Day 5 & Day 6 & Day 10 & Day 11 \\
\hline Francesco to parents & $1.7 \%$ & $6.8 \%$ & $2.9 \%$ & $1 \%$ & $7.7 \%$ \\
& $\mathrm{~N}=190$ & $\mathrm{~N}=177$ & $\mathrm{~N}=252$ & $\mathrm{~N}=169$ & $\mathrm{~N}=231$ \\
\hline Parents to Francesco & $0.6 \%$ & $2.1 \%$ & $3.5 \%$ & $1.4 \%$ & $2.7 \%$ \\
& $\mathrm{~N}=277$ & $\mathrm{~N}=275$ & $\mathrm{~N}=329$ & $\mathrm{~N}=307$ & $\mathrm{~N}=277$ \\
\hline
\end{tabular}

Similarly to what was noticed in the parents' dialect production, Francesco's dialect usage does not follow a clear direction. The child's Italian production ranges from $1.7 \%$ to $7.7 \%$. It rapidly increases between Day 1 and Day 5 and then is on the decrease from Day 5 to Day 6 and again to Day 10, where it is at its minimum. Francesco's dialect production then rises on Day 11 reaching the maximum production in this type of interaction. According to the Kruskal-Wallis tests, both Francesco and his parents change their dialect production significantly during their stay (for both speakers, $\mathrm{p} \leq 0.02$ ), yet do not show a clear direction.

The dialect productions reflecting the interactions between Francesco and the grandparents and the aunt reveal a different pattern. 


\section{LANGUAGE CHOICE ADJUSTMENTS IN CHILD PRODUCTION}

Table 5. Average percentages of dialect words in Francesco and the grandparents and aunt's production when they participate in the same interaction; number of utterances produced per day figure below percentages

\begin{tabular}{|l|l|l|l|l|l|}
\hline Pairs of interlocutors & Day 1 & Day 5 & Day 6 & Day 10 & Day 11 \\
\hline Francesco to Grandparents and & $4.6 \%$ & $3.7 \%$ & $9.3 \%$ & $12.7 \%$ & $10.5 \%$ \\
aunt & $\mathrm{N}=65$ & $\mathrm{~N}=90$ & $\mathrm{~N}=49$ & $\mathrm{~N}=51$ & $\mathrm{~N}=94$ \\
\hline Grandparents and aunt to & $2.8 \%$ & $5.8 \%$ & $6.5 \%$ & $9.1 \%$ & $10 \%$ \\
Francesco & $\mathrm{N}=268$ & $\mathrm{~N}=228$ & $\mathrm{~N}=144$ & $\mathrm{~N}=199$ & $\mathrm{~N}=228$ \\
\hline
\end{tabular}

Dialect production is on the increase within both interaction contexts: "Francesco to grandparents and aunt" and "Grandparents and aunt to Francesco". The child's dialect production range varies between $3.7 \%$ and $12.7 \%$ and the grandparents and aunt's dialect production range between $2.8 \%$ and $10 \%$. When the grandparents and the aunt speak to Francesco, they provide him with a steadily increasing dialect input from Day 1 to Day 11. As the Kruskal-Wallis tests show, these speakers' dialect production increases significantly throughout Francesco's stay in the grandparents' home $(\mathrm{p}=0.006)$. The Kruskal-Wallis tests reveal a similar tendency for Francesco's dialect production to increase during the vacation period spent at the grandparents' home $(\mathrm{p}=0.07)$.

Table 6 shows the Italian production which was observed in utterances produced in interactions in which the child and his parents participated.

Table 6. Average percentages of Italian words in Francesco and the parents' production when they participate in the same interaction; number of utterances produced per day figure below percentages

\begin{tabular}{|l|l|l|l|l|l|}
\hline Pairs of interlocutors & Day 1 & Day 5 & Day 6 & Day 10 & Day 11 \\
\hline Francesco to parents & $60.8 \%$ & $49.5 \%$ & $57.6 \%$ & $53.3 \%$ & $48.1 \%$ \\
& $\mathrm{~N}=190$ & $\mathrm{~N}=177$ & $\mathrm{~N}=252$ & $\mathrm{~N}=169$ & $\mathrm{~N}=231$ \\
\hline Parents to Francesco & $65.3 \%$ & $63.2 \%$ & $60.6 \%$ & $60.2 \%$ & $61.3 \%$ \\
& $\mathrm{~N}=277$ & $\mathrm{~N}=275$ & $\mathrm{~N}=329$ & $\mathrm{~N}=307$ & $\mathrm{~N}=277$ \\
\hline
\end{tabular}

The parents' Italian production does not change significantly during the vacation period $(\mathrm{p}=0.4)$. It remains between $65 \%$ and $60 \%$. Francesco's Italian production towards his parents changes significantly during the stay with a tendency to decrease significantly $(\mathrm{p}=0.005)$.

The Italian production in interactions involving Francesco and the "unfamiliar" interlocutors reveals a different pattern. 


\section{LANGUAGE CHOICE ADJUSTMENTS IN CHILD PRODUCTION}

Table 7. Average percentages of Italian words in Francesco and the grandparents and aunt's production when they participate in the same interaction; number of utterances produced per day figure below percentages

\begin{tabular}{|l|l|l|l|l|l|}
\hline Pairs of interlocutors & Day 1 & Day 5 & Day 6 & Day 10 & Day 11 \\
\hline $\begin{array}{l}\text { Francesco to Grandparents and } \\
\text { aunt }\end{array}$ & $57.8 \%$ & $60.5 \%$ & $57.3 \%$ & $53.3 \%$ & $48.1 \%$ \\
& $\mathrm{~N}=65$ & $\mathrm{~N}=90$ & $\mathrm{~N}=49$ & $\mathrm{~N}=51$ & $\mathrm{~N}=94$ \\
\hline Grandparents and aunt to & $62.9 \%$ & $64.2 \%$ & $60.2 \%$ & $57.5 \%$ & $53.3 \%$ \\
Francesco & $\mathrm{N}=268$ & $\mathrm{~N}=228$ & $\mathrm{~N}=144$ & $\mathrm{~N}=199$ & $\mathrm{~N}=228$ \\
\hline
\end{tabular}

First of all, the "unfamiliar" interlocutors change their Italian production significantly whilst interacting with the child $(\mathrm{p}=0.003)$. Despite the increase between Day 1 and Day 5, they seem to decrease their Italian production during most of the vacation period. In the utterances Francesco produces in this interaction context, his Italian production shows a statistical tendency towards decrease $(\mathrm{p}=0.10)$.

The four tables illustrate the changes in Francesco and his interlocutors' Italian and dialect productions during the eleven days. Of the four tables, the changes in the dialect productions are the most remarkable. Francesco steadily increases his dialect production when he is involved in exchanges with his grandparents and his aunt. These interlocutors use more dialect when interacting with Francesco than his parents do. In fact, during the 5 days of tapings, both Francesco and this group of speakers augment their dialect production. The latter stabilizes around $10 \%$ for both Francesco and his interlocutors. It is important to highlight that a progressive and convergent increase in dialect production is observed in both Francesco and his grandparents and aunt's productions. Hence, Francesco did not adjust to a stable source of dialect input as was observed in the mother-and-child dyads. Rather, the adjustments observed in the dialect production of Francesco and his interlocutors are progressive, coordinated and occur over a short period of time (eleven days). The characteristics of the child's adjustments observed in the multiparty interactions differ from those observed in the dyadic interactions with the mother and the differences examined will be discussed in the next section.

\section{Discussion}

In interactions within his nuclear family and with his extended family members, Francesco is provided with two main language choice patterns. In inter-adult speech, he is exposed indirectly to a predominantly dialect input, whereas in child-addressed-speech, Italian is the most frequently used language. Analysis of the child's production in dyadic interactions with his mother further underscores the impact of child-addressed speech on the child's language choices. In fact, from ages 17 to 30 months, Francesco gradually adjusts his production to that of his mother, particularly in the last two age periods. Similarly to what was previously found, 


\section{LANGUAGE CHOICE ADJUSTMENTS IN CHILD PRODUCTION}

Italian is the most represented language in dyadic interactions between Francesco and his mother, whereas dialect is produced less frequently. Usage of lexicon of the continuum category is almost always ranked in second place.

Francesco's exposure to the mother's input provides him with a relatively reliable source of recurring Italian form/function pairings. This would favor the acquisition and the utilization of these form/function pairings in the child's production. We have seen that with time, the language choices in the child's utterances are in close affinity with those in his mother's production. The process behind these adjustments could be that of statistical learning. Having the mother's reliable production as a target, the child would perceive the patterns in the input and use them in his production. These pattern-finding skills involved in language reception are at work during statistically-driven language acquisition processes (Tomasello 2003a). However, pragmatic learning is not excluded. In fact, the child could also be capable of selecting the appropriate languages according to the pragmatic intentions of his interlocutors.

In order to examine the child's ability to adjust his language choice according to pragmatic factors, we observed his production in a different setting: during multiparty interactions which took place in the grandparents' home. In the analyses of the input and output patterns, Francesco's various interlocutors were grouped in accordance to the amount of time they spend interacting with him. Hence, we grouped the two parents together and placed the grandparents and the aunt in the group of "unfamiliar" speakers. The close examination of language production provided several arguments in favor of pragmatic motivations guiding appropriate language choices in the child . In multiparty interactions, Italian remains the first choice in child-addressed speech and dialect remains the less frequently used language. Thus, the general language choice patterns are similar to those observed in the child's home. Yet language production does not vary in the same way as was observed in dyadic interactions. Generally, in the multiparty interactions dialect usage reveals significant changes in most speakers' productions (see Tables 3, 4 and 5), whereas in the mother-to-child dyadic interactions, dialect did not to change significantly throughout the length of the data collection (see Table 2). Two observations deserve attention in this regard. Firstly, both groups of adults reveal different dialect usages in the child-addressed speech: the child's parents use less dialect as opposed to the "unfamiliar" group of adults. Secondly, the child's production reveals similar dialect production variations as those observed in his addressees' usages. In interactions with his parents, Francesco's production is variable but it does not seem to follow a clear direction. Yet when the child interacts with the "unfamiliar" group of adults, his 


\section{LANGUAGE CHOICE ADJUSTMENTS IN CHILD PRODUCTION}

production reveals a relatively rapid (11 days) and coordinated adjustments to the group's dialect production. This type of convergence (short-term and coordinated) differs from the one observed in his home environment (long-term and not coordinated). In the multiparty interactions, the child does not adjust his language choices to a relatively stable target as in the mother-and-child dyadic interactions. Both Francesco and the group of "unfamiliar" interlocutors seem to adjust their language choices reciprocally. It is likely that this type of convergence is guided by the pragmatic factors underlying the interactions. Moreover, besides the nature of the convergence, it should be emphasized that the child has fewer opportunities to learn the dialect form/function pairings produced by the "unfamiliar" group of speakers as he systematically receives fewer utterances from these speakers than from his parents (cf. number of utterances in Table 3). Hence, considering that statistical learning is frequency dependent (Bybee 2008), Francesco's adjustments to the "unfamiliar" speakers is more likely to be accounted for by pragmatic motivations.

The production rates of vocabulary in the Italian and continuum categories are in first and second place respectively. Moreover, considering that the latter category contains lexicon that could figure in either Italian or dialect contexts of usage, the decisive usage of Italian in interactions involving the child could contribute to a progressive association of items in the continuum category to the predominantly Italian-speaking context. Hence, the continuum lexicon could be perceptually associated to the Italian lexicon in interactions involving the child, who is used to receiving a predominantly Italian input. Even slight variation in dialect usage would stand out more than variation in the most frequently used language. Dialect could then become more salient in its rarity - another argument in favor of a pragmatically motivated convergence. Givón discusses the notion of salience and argues that contrasting forms could accentuate the ones which are less frequently used (the "unmarked form"):

The notion of salience is fundamentally pragmatic, since saliency of a figure depends on how it stands out vis-à-vis the most frequent, predictable ground [...] The linguistic contrast of marked versus unmarked is fundamentally a frequency dependent figure/ground contrast [...] sooner or later the less frequent, marked form also becomes the perceptually more salient one (Givón 2005: 11-12).

Following Givón's argument, dialect would become the language which attracts the attention of both child and adult speakers, particularly during interactions involving the child directly. In its rarity, it could thus become the object of joint attention between the adult and the child, as revealed by the qualitative analysis of content of the interaction (Ghimenton 2010).

Tomasello (2003a) points out that it is within joint attentional interactions that children start using linguistic symbols. Within these types of interactions (or frames), children realize their 


\section{LANGUAGE CHOICE ADJUSTMENTS IN CHILD PRODUCTION}

social-interactional role in the exchanges. From an interactional perspective, joint attentional frames are prototypes of adult communication as the reciprocity it requires exposes the child to a conversational experience (Mueller \& Hoff 2006). Moreover, Tomasello (2003b) suggests that even language usage could be the object of joint attention. Dialect could indeed be the object of joint attention, as it has been suggested in a previous study on dialect acquisition in Veneto (Ghimenton \& Chevrot 2006). In this study, two sisters aged nine and five respectively produced and received mainly Italian. Despite the rare presence of dialect, the children showed signs of late dialect acquisition. The attention paid to dialect would render its usage more accessible to learning. Similarly, in the present case-study, salience due to dialect's rarity could make it become the object of joint attention between the child and the "unfamiliar" speakers and could favor its acquisition.

In Ghimenton (2010) excerpts of the content of the multiparty interactions were analyzed in detail. What emerged from the qualitative analyses were the differences in the parents' and grandparents' child-addressed speech. The former did not overtly favor the child's dialect production although they did use it sporadically for humorous purposes or even to assuage a reprimand. On the other hand, the grandparents encouraged Francesco to produce dialect by either answering him in dialect or by adopting an attitude of clear approval. More particularly, the grandfather attracts the attention of both Francesco and adults by repeating the dialect words the child uses. Thus, the grandparents' attitude to Francesco's dialect production seems to render this language more enticing for the child to use as it captures the adults' attention. More generally, the conversation with the grandparents creates numerous occasions for the production of dialect and for the development of a greater awareness of its use.

Below, we have reproduced an extract of an interaction between Francesco and the adults, during a meal. The grandmother is going to the kitchen and, in dialect, the grandfather asks her to bring two spoons for the fruit salad. The words which are underlined were placed in the dialect category whereas in italics and in bold are words which were placed in the Italian and continuum categories respectively. 
(2) Interaction between parents, grandparents, aunt and Francesco (25.19)

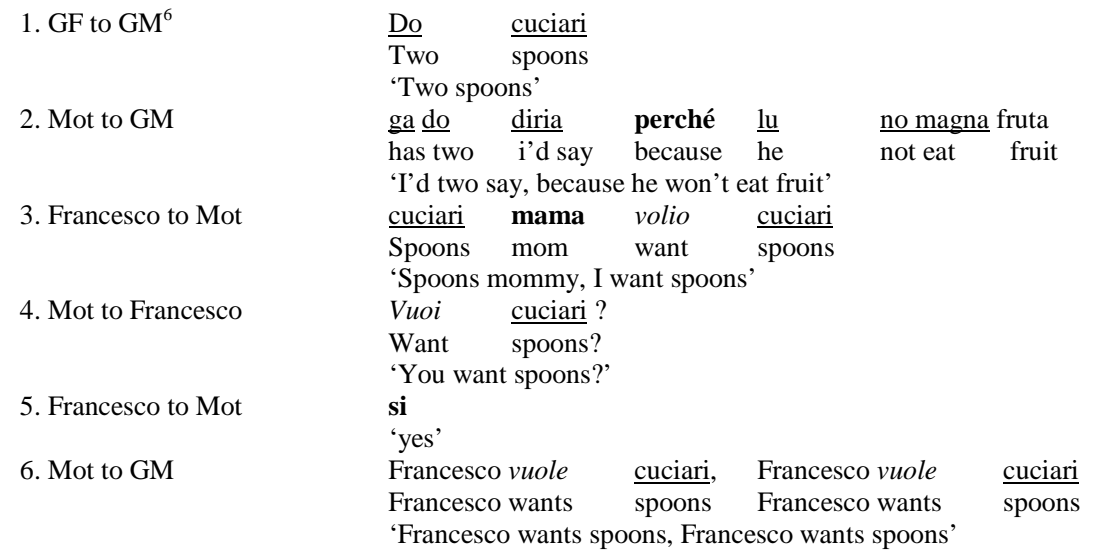

In line 2, Francesco's mother confirms that two spoons will suffice to eat the fruit salad, since Francesco will not be eating any. It should be noted that the mother does not overtly mention Francesco's name, but in dialect, she refers to him using the third person pronoun $l u$ in its singular form (dial. $l u$ 'him' $v s$ ita. lui). Immediately after the mother's turn, Francesco produces cuciari (dial. 'spoons', line 3 versus ita. cucchiai) inserting it with the modal verb 'want' conjugated in Italian, and forms the sequence want + noun (dialect). In his turn, he challenges his mother's initial supposition that he would not be needing a spoon. Francesco was not the direct addressee of the initial inter-adult exchange when cuciari (dial. 'spoons') was first produced by the grandfather (line 1) towards the grandmother. Moreover, his unusual dialect usage attracts the adults' attention, especially the mother's who, surprised by her son's dialect usage inserts the dialect word cuciari in all the speech turns she produced in this exchange, whereas the other words she used belong to the Italian lexicon. The child's retrieval of a dialect word produced within an inter-adult exchange suggests the child's sensitivity towards language produced in his environment. More importantly, the child has captured not only the dialect form cuciari but he has used it in order to convey his communicative intentions, that is attracting attention and obtaining a spoon. Reacting to Francesco's usage of dialect, the adults produce speech turns containing the dialect item he produced, creating numerous other opportunities for dialect exposure. In one exchange the child has been offered with various contexts in which different interlocutors use the item cuciari. It is not surprising then that the type-token ratio of Francesco's dialect production increases from 0.04 attested before leaving for South Africa to 0.9 observed in the period immediately after the vacation. The augmentation of the type token ration strongly suggests

\footnotetext{
${ }^{6}$ GF stands for 'grandfather'; GM stands for 'grandmother' and Mot stands for 'mother'.
} 


\section{LANGUAGE CHOICE ADJUSTMENTS IN CHILD PRODUCTION}

that the child has been undergoing lexical learning over the vacation. Another important point is that once the child returns to his home, in the period immediately following his vacation, his dialect production becomes again very low (see Table 2, age period 4, average percentages of dialect: $1.4 \%$ ) in comparison with his dialect production observed in the last two days of his stay. It then decreases steadily from $1.4 \%$ to $0.4 \%$ (see Table 2, age period 5). In light of these observations, what seems most likely to be at play is pragmatically oriented language usage. This means that Francesco is able to adjust his language choices according to his interlocutors' expectations. Moreover, the pragmatic salience of dialect usage in the multiparty interactions in South Africa as well as the increase of dialectal input could have favoured lexical learning of this language.

The principal aim of the work presented in this paper was to present a detailed analysis of the types of adjustments which can be observed at a very early stage in a child's production. Two types of adjustments were presented. The dominant characteristic underpinning the statistically-driven adjustments could be a long-term and progressive convergence to a relatively stable language target. Besides these statistical adjustments, we argued in favor of adjustments based on pragmatic motivations. The pragmatic hypothesis is supported by certain characteristics suggesting another type of pattern adjustments: short-term and coordinated convergence between the child and his interlocutors' productions. The characteristics of these two types of adjustments should be further investigated, reviewed and refined in future research in order to better understand the learning mechanisms underpinning language construction.

\section{References}

Alfonzetti, Giovanna. 1992. Il discorso bilingue. Italiano e dialetto a Catania. Milano: Franco Angeli.

Aslin, Richard N, Jenny R Saffran \& Elissa L Newport. 1998. Computation of Conditional Probability Statistics by 8-month-old Infants. Psychological Science. 9(4): 321-324.

Behrens, Heike. 2006. The input-output relationship in first language acquisition. Language and Cognitive Processes. 21(1-2): 2-24.

Bell, Allan. 1984. Language Style as Audience Design. Language in Society. 13: 145-204.

Berruto, Gaetano. 1974. La Sociolinguistica. Bologna: Zanichelli.

Berruto, Gaetano. 1993. Varietà del Repertorio. In Alberto Sobrero (ed.), L'Italiano Contemporaneo : La Variazione e gli Usi (Vol. II), 3-36. Roma-Bari: Laterza.

Berruto, Gaetano. 2005. Dialect/ Standard Convergence, Mixing, and Models of Language Contact: The Case of Italy. In Peter Auer, Frans Hinskens and Paul Kerswill (eds.), Dialect Change. Convergence and Divergence in European Languages, 81-95. Cambridge: Cambridge University Press.

Bybee, Joan L. 2008. Usage-Based Grammar. In Peter Robinson and Nick C Ellis (eds.), Handbook of Cognitive Linguistics and Second Language Acquisition, 216-236. London, New York: Routeledge. 


\section{LANGUAGE CHOICE ADJUSTMENTS IN CHILD PRODUCTION}

Bybee, Joan L. \& Paul Hopper. 2001. Introduction to Frequency and the Emergence of Linguistic Structure. In Joan L. Bybee and Paul Hopper (eds.), Frequency and the Emergence of Linguistic Structure, 1-24. Amsterdam, Philadelphia: John Benjamins.

Clark, Eve. 2009. First Language Acquisition (2 ed.). Cambridge, New York, Melbourne, Madrid, Cape Town, Singapore, Sao Paolo: Cambridge University Press.

Clark, Eve. 1978. Strategies for communication. Child Development. 49: 953-959.

Corrà, Loredana. 2001. I Veneti in Brasile : Koinè Dialettale come Superamento dei Confini. In Gianna Marcato (ed.), I Confini del Dialetto (Atti del convegno di Sappadal Plodn, Belluno, 5-9 Luglio 2000), 279-288. Padova: Unipress.

Cortelazzo, Manlio \& Ivano Paccagnella. 1997. Il Veneto. In Francesco Bruni (ed.), L'Italiano nelle Regioni : Volume 1 Lingua Nazionale e Identità Regionali (2 edn., Vol. 1), 220-281. Torino: Utet.

Cortelazzo, Manlio. 2001. Noi Veneti. Verona: Cierre Edizioni.

Coveri, Lorenzo, Antonella Benucci \& Pierangela Diadori. 1998. Le varietà dell'italiano: manuale di sociolinguistica italiana. Roma: Bonacci.

Dardano, Maurizio. 1994. Profilo dell'Italiano Contemporaneo. In Luciano Serianni and Pietro Trifone (eds.), Storia della Lingua Italiana, 343-430. Torino: Einaudi.

Dardano, Maurizio. 2005. Nuovo Manualetto di Linguistica Italiana (Vol. 1). Bologna: Zanichelli.

Döpke, Susanne. 1998. Competing language structures: the acquisition of verb placement by bilingual GermanEnglish children. Journal of Child Language. 25 (3): 555-584.

Fantini, Alvino E. 1985. Language Acquisition of a Bilingual Child: A Sociolinguistic Perspective. San Diego: College Hill Press.

Frosi, Vitalina Maria. 2001. L'Italiano Standard e i Dialetti Italiani in Brasile. In Gianna Marcato (ed.), I Confini del Dialetto (Atti del Convegno di Sappada/Plodn, Belluno, 5-9 luglio 2000) Padova: Unipress.

Gamberini, Gabrielle. 1999. Mise en Mots de la Structure Diglossique: le Cas de Venise. In Thierry Bulot (ed.), Langue Urbaine et Identité, 73-125. Paris: L'Harmattan.

Genesee, Fred, Isabelle Boivin \& Elena Nicoladis. 1996. Talking with Strangers: a Study of Bilingual Children's Communicative Competence. Applied Psycholinguistics. 17: 427-442.

Ghimenton, Anna \& Jean-Pierre Chevrot. 2006. Language Acquisition in a Multilingual Society; a Case Study in Veneto, Italy. In Frans Hinskens (ed.), Language Variation - European Perspectives, 71-81. Amsterdam: John Benjamins.

Ghimenton, Anna. 2010. Analyse d'interactions familiales entre trois générations dans la région italienne de Vénétie: réflexions sur les voies de la transmission des langues minorées. TRANEL. 52: 109-124.

Giacalone-Ramat, Anna. 1995. Code-Switching in the Context of Dialect/ Standard Language Relations. In Lesley Milroy and Pieter Muysken (eds.), One Speaker, Two Languages, 45-67. Cambridge, New York, Melbourne: Cambridge University Press.

Givón, Talmy. 2005. Context as other Minds: The Pragmatics of Sociality, Cognition and Communication. Amsterdam, Philadelphia: John Benjamins.

Goldberg, Adele, E. 2006. Constructions at Work. Oxford: Oxford University Press.

Grassi, Corrado, Alberto Sobrero \& Tullio Telmon. 1997. Fondamenti di Dialettologia Italiana. Roma, Bari: Laterza.

Gumperz, John J. 1977. Sociocultural Knowledge in Conversational Inference. In Muriel Saville-Troike (ed.), Linguistics and Anthropology Washington D.C: Georgetown University Press.

Gumperz, John J. 1982. Discourse Strategies. New York: Cambridge University Press.

Juan-Garau, Maria \& Carmen Perez-Vidal. 2001. Mixing and Pragmatic Parental Strategies in Early Bilingual Acquisition. Journal of Child Language. 28(1): 59-86.

Kuhl, Patricia, K. 2004. Early language acquisition: cracking the speech code. Neuroscience. 5 (4): 831-843.

Kuhl, Patricia, K. 2007. Is speech learning 'gated' by the social brain? Developmental Science, 10 (1): 110-120. 


\section{LANGUAGE CHOICE ADJUSTMENTS IN CHILD PRODUCTION}

Lanza, Elizabeth. 1992. Can Bilingual two-year-olds Code-switch? Journal of Child Language. 19: 633-658.

Lieven, Elena, Heike Behrens, Jennifer Speares \& Michael Tomasello. 2003. Early syntactic creativity : a usagebased approach. Journal of Child Language. 30: 333-370.

Lüdi, Georges \& Bernard Py. 1986. Etre Bilingue. Berne, Francfort, Main, New York: Peter Lang.

Macwhinney, Brian. 2005. A Unified Model of Language Acquisition. In Judith Kroll, F. and Annette M. B. Groot (eds.), Handbook of Bilingualism: Psycholinguistic Approaches, 49-67. New York: Oxford University Press.

Marcato, Carla. 2002. Il Veneto. In Manlio Cortelazzo, Carla Marcato, Nicola De Blasi and Gianrenzo Clivio, P. (eds.), I Dialetti Italiani, 296-328. Torino: Utet.

Marcato, Gianna \& Flavia Ursini. 1998. Dialetti Veneti: Grammatica e Storia. Padova: Cleup.

Marchiaro, Silviana. 2001. Lingua e Dialetto fra gli Immigrati Italiani a Cordoba. In Gianna Marcato (ed.), I Confini del Dialetto (Atti del Convegno di Sappada/Plodn, Belluno, 5-9 Luglio 2000), 245-252. Padova: Unipress.

Mondada, Lorenza. 2007. Le Code-Switching comme Ressource pour l'Organisation de la Parole-en-Interaction. Journal of Language Contact. THEMA 1: 168-197.

Moore, Danièle. 2002. Code-Switching and Learning in the Classroom. International Journal of Bilingual Education and Bilingualism. 5(5): 279-293.

Mueller, Virigina C \& Erika Hoff. 2006. Input and the Acquisition of Language: Three Questions. In Erika Hoff and Marilyn Shatz (eds.), The Handbook of Language Development, 107-127. Blackwell Publishers.

Nicoladis, Elena. 1998. First Cues to the Existence of Two Input Language: Pragmatic and Lexical Differentiation in a Bilingual Child. Bilingualism: Language and Cognitfon. 1: 105-116.

Pearson, Barbara Zurer, Fernandez, Sylvia, Lewedag, Vanessa \& Oller, D. Kimbrough. 1997. Input factors in lexical learning of bilingual infants (ages 10 to 30 months). Applied Psycholinguistics, 18: 41-58.

Perruchet, Pierre \& Pacton, Sébastien. 2006. Implicit learning: one phenomenon, two approches. Trends in Cognitive Sciences, 10 (5): 233-235.

Poletto, Cecilia. 2000. The Higher Functional Field: Evidence from Northern Italian Dialects. Oxford: Oxford University Press.

Quay, Suzanne. 2008. Dinner Conversations with a Trilingual two-year-old: Language Socialization in a Multilingual Context. First Language. 28(1): 5-33.

Tomasello, Michael. 2000. The Social-Pragmatic Theory of Word Learning. Journal of Pragmatics. 10(4): 401413.

Tomasello, Michael. 2003a. Constructing a Language. A Usage-based Theory of Language Acquisition. Cambridge/ Massachusetts, London/ England: Harvard University Press.

Tomasello, Michael. 2003b. The Key is Social Cognition. In Dedré Gentner and Susan Goldin-Meadow (eds.), Language in Mind: Advances in the Study of Language and Thought, 47-57. Cambridge, Massachusetts: MIT Press.

Zamboni, Alberto. 1979. Le caratteristiche essenziali dei dialetti veneti. In Guida ai dialetti veneti (Vol. 0), 9-43. Padova: Cleup.

Zamboni, Alberto. 1998. Die Historische Klassifikation der Romania IV. Italoromanisch. In Günter Holtus, Michael Meltzeltin and Christian Schmitt (eds.), Lexikon der Romanistischen Linguistik (Vol. VII), 948-955. Tübingen: Max Niemeyer Verlag.

Zamboni, Alberto. 2002. I Dialetti e le loro Origini. In Manlio Cortelazzo, Carla Marcato, Nicola De Blasi and Gianrenzo P Clivio (eds.), I Dialetti Italiani: Storia, Struttura, Uso. Torino: UTET.

Zentella, Ana Celia. 1997. Growing up Bilingual: Puerto Rican Children in New York. Oxford: Blackwell Publishers. 